\title{
Avaliação da gestão dos resíduos sólidos de saúde da Irmandade Santa Casa de Caridade de São Gabriel-RS sob a ótica da nova Legislação Brasileira.
}

\author{
Evaluation of solid waste management health of the Brotherhood of Santa San Gabriel-RS \\ charity house from the perspective of the new Brazilian legislation.
}

\author{
Ana Paula da Motta Pereira e Beatriz Stoll Moraes \\ Universidade Federal do pampa -Campus São Gabriel \\ paula_consagua@hotmail.com; beatrizstoll@gmail.com
}

\begin{abstract}
Resumo
A crescente consciência sobre os riscos à saúde publica e ao meio ambiente provocados por resíduos sólidos gerados nos serviços de saúde deve-se, principalmente, às suas frações infectantes. No Brasil, há milhares de unidades de saúde produzindo esses resíduos, e na maioria das cidades, a questão do manuseio e da disposição final é um grande problema. A Santa casa de Caridade de São Gabriel-RS reconhecendo sua responsabilidade como geradora de resíduos de saúde buscou no ano de 2008 adequar-se a legislação a fim de minimizar impactos ambientais e sociais. Com isto o presente estudo buscou analisar as condições de gerenciamento dos resíduos sólidos do serviço de saúde produzidos pela Irmandade da Santa Casa de Caridade, através de pesquisa exploratória, com o objetivo de verificar o atendimento aos padrões legais existentes. O estudo utilizou como base a resolução da diretoria colegiada (DC) 306/2004 da Agência Nacional de Vigilância Sanitária (ANVISA), a resolução 358/2005 do Conselho nacional do meio ambiente (CONAMA) e a lei 12.305 de 2010 Política Nacional dos Resíduos Sólidos. Com esta pesquisa foi possivel identificar pontos fortes e fracos na gestão dos resíduos bem como algumas adequações que serão necessárias em função da legislação vigente.
\end{abstract}

Palavras-chave: Resíduos sólidos de saúde (RSS). Gerenciamento dos RSS. Legislação aplicada aos RSS.

\begin{abstract}
The increasing awareness about the risks on public health and environment, caused by solid residues generated by health service, is mainly due to its infectious fractions. In Brazil, there's thousand health units producing these residues and, in most cities, the handling issue and final arrangement are not yet resolved. The Irmandade da Santa Casa of São Gabriel, RS, acknowledging its responsability as generator of health residues sought to adjust to the legislation and minimize the impacts caused on the environment and others afected by its activities. Thus, the present study sought to, through exploratory research, analyze the conditions of the management of solid wastes on health services which are produced by Irmandade da Santa Casa in order to verify the compliance with the existing legal standards. The present study used the resolution of the executive board ( DC) 306/2004 of the National Health Surveillance Agency ( ANVISA), the Resolution 358/2005 of the National Environment Council ( CONAMA), and 201012.305 law which establishes the national policy on solid waste to evaluate and compare the reality of the institution. Through research it was possible to identify strengths and weaknesses on the management of waste as well as some necessary adjustments based on the current legislation.
\end{abstract}

Keywords: Solid health residues. Management. Legislation. 


\section{Introdução}

Segundo a Associação Brasileira de Normas Técnicas NBR 10004/2004 os resíduos sólidos são os resíduos no estado sólidos e semissólido que resultam das atividades da comunidade, de origem industrial, doméstica, hospitalar, comercial, agrícola, de serviços e de varrição. Os resíduos do serviço de saúde tema do presente estudo são definidos por Ribeiro e Morelli (2009), como resíduos descartados por hospitais, clínicas, farmácias, laboratórios, postos de saúde clínicas veterinárias etc. Estes representam segundo a última Pesquisa Nacional de Saneamento Básico (IBGE-PNSB, 2008) uma fração de $2 \%$ do total de resíduos sólidos gerados no Brasil e destes $2 \%$ apenas 10 a $25 \%$ necessitam de cuidados especiais. Grippi (2006) afirma que os resíduos de saúde constituem os resíduos sépticos que contêm ou potencialmente podem conter germes patogênicos. Os resíduos sólidos de saúde por possuírem um potencial infeccioso degradante e poluente contra o meio ambiente e contra a saúde humana, exigem atenção especial e técnicas corretas de manejo e gerenciamento.

No Brasil, até a década de 90, os resíduos produzidos por hospitais não eram alvo de nenhuma preocupação, eram acondicionados de qualquer maneira, geralmente em sacos impermeáveis e o local de armazenamento temporário era a céu aberto, sujeito a intempéries e aos animais, que muitas vezes espalhavam resíduos pelas áreas externas dos hospitais (DIAS, 2004, p.25 apud TOLEDO, 2011, p.23).

Em 1983 segundo uma fonte do Ministério da Saúde e do INAMPS, houve no Brasil 12.000.000 casos de internações e estima-se que 700.000 pessoas contraíram infecção hospitalar, sendo que pelo menos 70.000 destes por resíduos hospitalares (BUSCH, 1993). O aumento da quantidade e toxidade destes resíduos produzidos atualmente, bem como a necessidade de destinação e tratamento adequado são questões cada vez mais relevantes para se atingir o desenvolvimento sustentável (TONANI, 2011). Para Schneider et al (2001), os principais fatores que contribuem para o aumento dos resíduos de saúde estão relacionados as complexidades médicas a crescente utilização de material descartável e aliado a isso o aumento da população idosa que normalmente necessita mais do serviço de saúde. Diante disso, nos últimos anos políticas públicas têm sido discutidas e legislações e normas elaboradas com vistas a garantir o desenvolvimento sustentável e a preservação da saúde pública. O presente estudo teve como principal objetivo analisar o gerenciamento dos resíduos sólidos de saúde da Irmandade da Santa Casa de São Gabriel-RS, bem como vislumbrar o cumprimento das principais normas legais vigentes.

\section{Metodologia}

O estudo foi realizado inicialmente, por meio de uma pesquisa bibliográfica através de livros, revistas, artigos acadêmicos, documentos e as leis acerca dos resíduos sólidos de saúde, após obter estas informações foi possível realizar as observações in loco e realizar as entrevistas com a gestora do centro de controle de infecção hospitalar, responsável por toda a gestão dos resíduos na Santa casa. Como instrumento para a coleta de dados utilizou-se questionários com perguntas abertas e fechadas, estas perguntas foram feitas com base na resolução da diretoria colegiada RDC 306/2004 como forma de check list para comparar as exigências normativas com as práticas da instituição. Após o levantamento de informações teóricas e práticas foram analisadas as metodologias utilizadas no processo de gestão dos resíduos sólidos de saúde produzidos pela instituição e também foi possível visualizar se os mesmos estavam em conformidade com as resoluções, normatizações, decretos e leis vigentes.

\subsection{Os Resíduos Sólidos do Serviço de} Saúde e a Legislação Vigente. 
Os resíduos sólidos e seus riscos começaram a ser considerados como questão ambiental somente a partir da década de 70. Em 1979 a portaria do Ministério dos Interiores, determinou que todos os resíduos referentes ao serviço de saúde fossem obrigados a serem incinerados, mas em 1991 a resolução $n^{0} 06$ do CONAMA desobrigou desta incineração. Em 1981, o Governo Federal através da lei $\mathrm{n}^{\mathrm{o}}$ 6.938, instituiu a Política Nacional do Meio Ambiente, pelo qual foram criados o Sistema Nacional do Meio Ambiente (SISNAMA) com a finalidade de estabelecer um conjunto articulado de órgãos, entidades, regras e práticas responsáveis pela proteção e pela melhoria da qualidade ambiental e a criação do Conselho Nacional do Meio Ambiente (CONAMA). O CONAMA estabelece padrões regulamentadores referentes ao meio ambiente, onde os resíduos sólidos de saúde possuem regulamentações específicas.

A resolução CONAMA $n^{\circ} 358 / 05$ trata do gerenciamento dos RSS sob o prisma da preservação dos recursos naturais e do meio ambiente estabelecendo critérios para o licenciamento ambiental dos sistemas de tratamento e destinação final.

Já a norma RDC 306/2004 conceitua e normatiza a forma de manejo dos RSS da seguinte forma:

Segregação: Consiste na separação dos resíduos no momento e local de sua geração, de acordo com as características físicas, químicas, biológicas, seu estado físico e os riscos envolvidos.

Tratamento: Consiste na aplicação de método, técnica ou processo que modifique as características dos resíduos, reduzindo ou eliminando o risco de contaminação, de acidentes ocupacionais ou de danos ao meio ambiente. Esse tratamento pode ser realizado através da esterilização, desinfecção ou incineração.

Acondicionamento: Consiste no ato de embalar os resíduos segregados, em sacos ou recipientes para que evitem vazamentos e resistam às ações de punctura e ruptura. A capacidade dos recipientes de acondicionamento deve ser compatível com a geração diária de cada tipo de resíduo.

Identificação: Consiste no conjunto de medidas que permite o reconhecimento dos resíduos contidos em sacos e recipientes, fornecendo informações ao correto manejo dos RSS.

Transporte Interno: Consiste no traslado dos resíduos dos pontos de geração até o local destinado ao armazenamento temporário ou armazenamento externo de apresentação para a coleta.

Armazenamento: Consiste na guarda dos recipientes contendo os resíduos acondicionados. O local do armazenamento localiza-se na parte externa ao prédio, no pátio, devidamente identificadas as áreas de acordo com o resíduo contido. Ficando ali dispostos ate chegada do transporte apropriado para sua disposição final.

Coleta e transporte externo: Consistem na remoção dos RSSS do armazenamento até a unidade de tratamento ou disposição final, utilizando-se técnicas que garantam a preservação das condições de acondicionamento e a integridade dos trabalhadores, da população e do meio ambiente, devendo estar de acordo com as orientações dos órgãos de limpeza urbana.

Os resíduos sólidos de saúde são classificados da seguinte forma:

Tabela 1 - Classificação dos RSS pelas resoluções da ANVISA RDC 358/2004 e CONAMA n³58/05

\begin{tabular}{cc}
\hline Grupo & Características \\
\hline A & Biológico \\
B & Químico \\
C & Radioativo \\
D & Resíduos Comuns \\
E & Perfurocortantes \\
\hline
\end{tabular}


Devido à sua patogenicidade, os resíduos sólidos de saúde (RSS) são classificados como classe I, perigosos, código de identificação D004, conforme a norma ABNT NBR 10.004 (2004). Ainda segundo a NBR 10.004/2004, a legislação vigente estabelece que os geradores de RSS estejam sujeitos à elaboração de Plano de Gerenciamento de Resíduos Sólidos e os serviços de coleta e transporte são de sua responsabilidade.

\section{Discussões e Resultados}

O estudo realizou-se no período de 13 de dezembro de 2014 a 03 de fevereiro de 2015 na Irmandade da Santa Casa de Caridade de São Gabriel-RS, uma das instituições mais antigas e de grande importância para o município. A Santa Casa de São Gabriel está inscrita sob o CNPJ: 96.593.322/0001-60 está situada na Rua General Marque n ${ }^{\circ} 72$ no centro de São Gabriel, é uma instituição filantrópica, que deu início aos seus trabalhos em 15 de abril de 1855 e atualmente consta com 194 leitos, 521 funcionários e funciona 24horas por dia atendendo um público aproximado de 195 pacientes ao dia. A Irmandade está em plena atividade de expansão e possui uma área construída de $9.293 .52 \mathrm{~m}^{2} \mathrm{e}$ a área total do terreno de $13.886 .60 \mathrm{~m}^{2}$ utiliza-se de nove reservatórios de abastecimento de água de rede pública e lança seus efluentes líquidos direto na rede de esgoto pública. Suas especialidades médicas são: urologia, gineco-obstetrícia, otorrinolaringologia, cardiologia, ortopedia, traumatologia, medicina interna, oftalmologia, neuropediatria, anestesiologia, pediatria, nefrologia, endocrinologista, patologia, psiquiatria, clínica geral, cirurgia plástica, reumatologia, pneumologia, neurocirurgia e gastroenterologia. A empresa implementou seu plano de gestão dos resíduos sólidos de saúde em 2008 e sua última atualização ocorreu em dezembro de 2014. Atualmente a instituição vem gerando mensalmente 8.932 litros de resíduos de saúde que necessitam de cuidados e tratamentos especiais de alto custo para a instituição e $8.820 \mathrm{~kg}$ de materiais que podem ser reciclados e outros coletados pela rede municipal que trata dos resíduos urbanos. tabela 2:

Subdivisão conforme categoria esta descrita na

Tabela 2 - Categoria e quantidade de resíduos de saúde coletados mensalmente

\begin{tabular}{cc}
\hline Grupo & Total Resíduos/Mês \\
\hline A & 7.868 Litros \\
B & 420 Litros \\
C & Não possui \\
D & $2.800 \mathrm{Kg}$ \\
E & $644 \mathrm{Litros}$ \\
Recicláveis & $4.620 \mathrm{Kg}$ \\
Específicos & $1.400 \mathrm{Kg}$ \\
\hline
\end{tabular}

A trajetória dos resíduos de saúde da Santa Casa de São Gabriel tem seu início no setor do Centro de Controle de Infecção Hospitalar CCIH onde ocorre treinamento duas a três vezes no ano do quadro de funcionários com orientações pertinentes ao assunto, tanto no que se refere a separação propriamente dita como também na segurança das pessoas envolvidas diretamente com o manuseio dos resíduos. Ao visitar os setores, foi possível verificar em cada setor, a separação de acordo com sua categoria, este processo é denominado segregação o que é muito importante para que não haja a contaminação dos resíduos a serem reciclados e com os resíduos comuns que irão para o serviço de coleta urbana. A segregação é o ponto fundamental de toda a discussão 
sobre a periculosidade ou não dos resíduos de serviços de saúde. Apenas uma parcela é potencialmente infectante, contudo, se ela não for segregada, todos os resíduos que a ela estiverem misturados também deverão ser tratados como potencialmente infectantes, exigindo procedimentos especiais para acondicionamento, coleta, transporte e disposição final, elevando assim os custos do tratamento desses resíduos (GARCIA; ZANETTIRAMOS, 2004).

Os resíduos infectantes, químicos $\mathrm{e}$ perfurocortantes gerados pela Santa casa são coletados e transportados uma vez por semana por uma empresa terceirizada denominada Stericycle Gestão Ambiental LTDA. Esta possui um caminhão baú que toda a quartafeira sem horário definido vem a Santa casa e faz a coleta e transporte dos resíduos para sofrerem o processo de tratamento e disposição final.

Para realizar este serviço à empresa Stericycle cobra um valor em função da quantidade gerada em kg. O custo para a Santa casa segundo o centro de controle de infecção hospitalar fica entorno de $\mathrm{R} \$ 5.000,00$ por mês para pagar o transporte, tratamento e disposição final.

Os resíduos comuns são coletados todos os dias da semana exceto domingo pela empresa Ansus-Serviços LTDA. que é a mesma que presta o serviço de limpeza pública no município. O caminhão de transporte é um caminhão compactador. Atualmente os resíduos urbanos do município estão sendo transportados para Santa Maria$\mathrm{RS}$, devido o município não possuir um aterro que atenda a legislação vigente. Já o material que pode ser reciclado é coletado pela empresa Reciclagem Paraíso, que faz a coleta dos resíduos específicos (entulho, móveis, eletroeletrônicos, lâmpadas fluorescentes, etc.) todos os dias e recicláveis uma vez por semana (vidro, metal, papel, papelão e plástico).

A Santa Casa possui uma equipe de coleta fixa que recebe treinamento e material de segurança para trabalhar. Esta mesma equipe auxilia e acompanha os terceiros (Ansus, Stericycle e Reciclagem Paraíso) que irão fazer a coleta do material na unidade de armazenamento. A coleta interna (Figura 1): Coleta dos resíduos infectantes realizada por esta equipe possui roteiro e horários previamente definidos, para não coincidir com a distribuição de roupas, alimentos e medicamentos, períodos de visita ou de maior fluxo de pessoas ou de atividades. Geralmente a coleta ocorre três vezes ao dia nos horários 9h, 13h e 18h30. No momento da coleta os resíduos (Figura 2) já estão separados ou segregados e acondicionados em sacos conforme sua categoria e se necessário são identificados através de etiquetas simples.

Observando os processos operacionais de segregação, acondicionamento, identificação, transporte interno, armazenamento temporário, armazenamento externo, coleta e transporte externos a instituição está de acordo com as normas da RDC 306/2004.

Já nos processos gerenciais conforme as normas da RDC 306/2004 foram detectados alguns pontos que necessitam de reestruturação, como a necessidade de um profissional responsável com ART ou certificado de responsabilidade técnica para a gestão e implantação do plano de gerenciamento, pois a profissional responsável não atende as qualificações exigidas pela legislação.

O Hospital também não realiza auditoria nas empresas coletoras de RSS para verificar se ocorre à destinação correta dos RSS, ou se está atendendo a legislação ambiental, podendo desta forma, a instituição hospitalar ser co-responsável em caso de um acidente ou contaminação ambiental.

Quanto aos resíduos da classe C que são os resíduos radioativos é necessário fazer o controle da quantidade dos mesmos, como pode ser observado na tabela 2, a instituição não os quantifica.

Quanto ao Plano de Gestão dos Resíduos Sólidos de Saúde à instituição necessita criar ações em situação de emergência e acidentes, desenvolver instrumentos de avaliação e controle, incluindo indicadores claros, 
objetivos, auto-explicativos e confiáveis, que permitam acompanhar a eficácia do PGRSS implantado.

As medidas de desempenho são sinais vitais da organização, elas qualificam e quantificam o modo como as atividades ou resultados de um processo atingem suas metas (HRONEC, 1993).

Hronec (1993) afirma que o uso de uma ferramenta de avaliação de desempenho a uma estrutura do PGRSS apresenta as seguintes vantagens:

- Permite acompanhar e concentrar os esforços naqueles fatores que são mais importantes para a redução dos riscos no estabelecimento;

- Mostra a eficiência no uso dos recursos do hospital;

- Fornece informações sobre as causas e origens dos problemas;

- Demonstra quais são os impactos das ações geradas dentro do PGRSS.

Os resíduos líquidos provenientes de esgoto e de águas servidas de estabelecimento de saúde devem ser tratados antes do lançamento no corpo receptor ou na rede coletora de esgoto, sempre que não houver sistema de tratamento de esgoto coletivo atendendo a área onde está localizado o serviço, conforme definido na RDC ANVISA no. 50/2002.

No tocante a um planejamento estratégico onde englobaria alguns objetivos da lei 12.305/2010 como estímulo à adoção de padrões sustentáveis de produção e consumo de bens e serviços; adoção, desenvolvimento e aprimoramento de tecnologias limpas como forma de minimizar impactos ambientais; redução do volume e da periculosidade dos resíduos perigosos; articulação entre as diferentes esferas do poder público, e destas com o setor empresarial, com vistas à cooperação técnica e financeira para a gestão integrada de resíduos sólidos; não foi possível observar no PGRSS desta instituição.

\section{Conclusões}

Ressalta-se que nenhuma situação é estática por isso o plano deve ser avaliado de modo cíclico, pois deve ser ajustado continuamente de acordo com os contextos sempre mutáveis. $\mathrm{O}$ sucesso de qualquer trabalho depende muito da maneira como são escolhidos os membros de uma equipe e de como eles utilizam os recursos, como dividem o trabalho e normatizam sua relação interna (para a comunicação, a gestão de conflitos e outros processos). Vilela Júnior e Demajorovic (2006), afirmam que a cada dia as empresas estão tendo que competir num ambiente de negócio cada vez mais complexo, no qual não é mais suficiente obedecer às leis e pagar impostos. As instituições de sucesso serão cada vez mais pressionadas para olhar intensamente o impacto das suas operações dentro e fora de suas paredes e cuidadosamente verificar os impactos de suas políticas e ações em seus empregados, clientes comunidades e na sociedade como um todo. A pesquisa revelou que o hospital não contempla alguns quesitos exigidos, de acordo com a RDC n³06/2004 da ANVISA, faltando alguns procedimentos para enquadrar-se em um PGRSS adequado. Também foi possível observar a falta de estratégias, critérios técnicos e administrativos, padrões de operações e minimização de resíduos de potencial perigo dentro do PGRSS do hospital.

Com a pesquisa foi possível concluir que o gerenciamento dos resíduos sólidos de saúde apenas para o cumprimento da legislação vigente no âmbito operacional não resolve o problema em toda a sua magnitude. Para que o problema seja resolvido de forma ampla é necessário que haja envolvimento e conscientização de toda organização assim como toda a população envolvida.

\section{Referências}

ASSOCIAÇÃO BRASILEIRA DE NORMAS TÉCNICAS. NBR 10004: resíduos sólidos classificação. Rio de Janeiro, 2004.

BRASIL. Agência Nacional de Vigilância Sanitária. Resolução da Diretoria Colegiada - RDC No 50 , de 21 de fevereiro 2002. 
BRASIL. Agência Nacional de Vigilância Sanitária. Resolução da Diretoria Colegiada - RDC No 306, de 7 de dezembro de 2004. Dispõe sobre o Regulamento Técnico para o gerenciamento de resíduos de serviços de saúde.

Brasil. CONAMA. (2005). Resolução no 358, de 29 de abril de 2005. Dispõe sobre o tratamento e a disposição final dos resíduos dos serviços de saúde e dá outras providências. Diário Oficial da República Federativa do Brasil, Brasília (DF), 04 de maio de 2005.

Brasil. CONAMA. Resolução nº de 19 de setembro de 1991. Dispõe sobre o tratamento de resíduos sólidos provenientes de estabelecimentos de saúde, portos e aeroportos. Diário Oficial da República Federativa do Brasil, Brasília (DF), 30 de outubro 1991.

BRASIL. Portaria do Ministério do Interior - MINTER $\mathrm{n}^{\circ}$ 53, de $1^{\circ}$ de março de 1979 - Dispõe sobre o tratamento e disposição final de resíduos sólidos de qualquer natureza.

BRASIL. Lei $n^{\circ}$ 6.938, de 31 de agosto de 1981. Dispõe sobre a Política Nacional do Meio Ambiente, seus fins e mecanismos de formulação e aplicação e dá outras providências.

BRASIL. Lei $n^{\circ} 12.305$, de 02 de agosto de 2010. Institui a Política Nacional de Resíduos Sólidos; altera a Lei no 9.605 , de 12 de fevereiro de 1998; e dá outras providências.

GARCIA, L. P.; ZANETTI-RAMOS, B. (2004) Gerenciamento de Resíduos de Serviços de Saúde: uma questão de biossegurança. Cad. Saúde Pública, v.20 n.3. Rio de Janeiro, maio/junho, 2004.

GRIPPI, S. (2006) Lixo, reciclagem e sua história: guia para as prefeituras brasileiras. 2 ed. Rio de Janeiro: Interciência, 2006.

HRONEC, S. M. (1993). Sinais Vitais: usando medidas de desempenho da qualidade, tempo e custom para traçar a rota para o futuro de sua empresa. Arthur Andersen. São Paulo: Makron Books. 1993.

Instituto Brasileiro de Geografia e Estatístico-IBGE. 2008. Pesquisa Nacional de Saneamento Básico. Rio de Janeiro. 219p. Disponível em: http://www.ibge.gov.br/home/estatistica/populacao/co ndicaodevida/pnsb2008/PNSB_2008.pdf. Acessado em 18 agosto 2015 .

RIBEIRO, D. V.; MORELI, M. R. (2009). Resíduos sólidos: problema ou oportunidade?-Rio de Janeiro: Interciência, 2009.

SCHNEIDER, E. S.; et al. (2001) Manual de gerenciamento de resíduos sólidos de serviço de saúde. São Paulo: Editora CLR Balieiro, 2001.

TOLEDO, A. F. de. (2011). Gestão ambiental em hospitais. São Caetano do Sul, SP: Yendis Editora, 2011.

TONANI, P. (2011). Responsabilidade decorrente da poluição por resíduos sólidos: de acordo com a Lei 12.305/2010- Institui a Política Nacional de Resíduos Sólidos. 2.ed. rev., atual. e ampl.- Rio de Janeiro: Forense: São Paulo: Método, 2011.

VILELA JUNIOR, A.; DEMAJOROVIC, J. Modelos e Ferramentas de Gestão Ambiental Desafios e perspectivas para as organizações. Editora Senac São Paulo, 2006. 